\title{
REFLEXÕES PRELIMINARES SOBRE PALEOEPIDEMIOLOGIADA VIOLÊNCIA EM GRUPOS CERAMISTAS LITORÂNEOS: (I) SÍTIO PRAIA DA TAPERA - SC
}

Andrea Lessa*

\begin{abstract}
LESSA, A. Reflexões preliminares sobre paleoepidemiologia da violência em grupos ceramistas litorâneos: (I) Sítio Praia da Tapera - SC. Rev. do Museu de Arqueologia e Etnologia, São Paulo, 15-16: 199-207, 2005-2006.
\end{abstract}

RESUMO: Foram analisados os traumas agudos associados à violência na amostra esquelética do sítio Praia da Tapera (SC), composta por 71 indivíduos adultos de ambos os sexos. Os traumas considerados foram as fraturas no crânio, na face e na ulna, e as lesões causadas por pontas de projétil. Apenas os indivíduos associados ao segundo momento de ocupação do sítio apresentaram traumas, tendo sido os homens mais afetados do que as mulheres (17,2\% e 3,8\% respectivamente). As interpretações ainda preliminares para a ocorrência dos conflitos estão relacionadas a elementos ideológicos e padrão de subsistência em uma perspectiva geral. Uma reflexão mais particular para o sítio relacionou os conflitos à sua localização estratégica, ou ainda à tentativa de rapto de mulheres.

UNITERMOS: Paleoepidemiologia - Trauma agudo-Violência-Grupos ceramistas - Litoral - Santa Catarina.

\section{Introdução}

O fenômeno da violência entre populações pré-históricas vem sendo considerado em todo o mundo um importante aspecto do comportamento humano, capaz de revelar semelhanças e diferenças nas causas, na intensidade e nas formas de se lidar com os conflitos ao longo dos tempos.

A ruptura temporária de mecanismos que balizam as relações de convívio intra e intergrupais, bem como o rearranjo permanente dos papéis sociais, são os principais fatores que alimentam situações potenciais de violência (Lessa e Mendon-

(*) Escola Nacional de Saúde Pública / FIOCRUZ. lessa@ensp.fiocruz.br ça de Souza 2001; Lessa 2004). A estreita relação entre os diferentes padrões de violência e o contexto histórico específico em que os eventos estão inseridos confirmam a sua importância enquanto ferramenta para compreensão do modo de vida de populações pretéritas.

Apesar do potencial informativo representado pelo tema, ainda são escassos os estudos específicos sobre traumas agudos associados à violência em material esquelético brasileiro. Uma primeira abordagem foi realizada por Lessa e Medeiros (2001) para populações construtoras de sambaquis, mas muito ainda deve ser feito para que possa ser esboçado um quadro geral sobre a agressividade em grupos litorâneos.

Com o presente trabalho, buscou-se dar continuidade a esta reflexão inicial, ampliando as análises para amostras provenientes de outro tipo 
de sítio litorâneo, representado pela aldeia de Praia da Tapera (SC).

\section{Contextualização}

Segundo Rohr (1966), o sítio da Praia da Tapera, denominado jazida paleoetnográfica, ${ }^{1}$ não apresenta as características de um sambaqui, uma vez que não apresenta conchas em muitas áreas. Onde elas ocorrem, o nível apresenta pouca espessura, oscilando ao redor de $20 \mathrm{~cm}$, além de estar misturado com elevado teor de húmus.

Na definição proposta por Prous (1992), nos sítios deste tipo os vestígios culturais estão contidos dentro de uma matriz sedimentar composta, na sua maior parte, de elementos minerais, e dentro da qual as conchas de moluscos, embora presentes, constituem uma parte mínima do volume do sítio. A partir das datações disponíveis, podem ser subdivididos em acampamentos "antigos", sem presença de cerâmica, e "recentes”, geralmente associados à Tradição Itararé.

Localizado em uma pequena enseada da Baía Sul da Ilha de Santa Catarina, o sítio reas, e onde elas ocorrem o n que na Tapera.dade sa por Lessa e Medeiros (2001) para população foi totalmente escavado por João Alfredo Rohr no início da década de 60, totalizando uma área de pouco mais de $2.000 \mathrm{~m}^{2}$ (Rohr 1966). O local foi ocupado por duas tradições ceramistas: a Itararé com datações radiocarbônicas de $810 \pm 180$ d.C. (SI-245) (camada C) e $920 \pm 180$ d.C. (SI-246) (camada B), e a Tupiguarani com datação de $1.400 \pm 70$ d.C. (SI 144) (camada A) (Rohr 1966; Silva et al. 1990).

Foram coletados 172 esqueletos, todos associados à ocupação Itararé, dos quais 74 são crianças e adolescentes até 16 anos, e 98 são adultos de ambos os sexos. Através da distribuição espacial dos sepultamentos, foi possível estabelecer três momentos de ocupação anteriores à ocupação Tupiguarani (Silva et al. 1990).

(1) Esses sítios também são denominados acampamentos litorâneos e sambaquis rasos. Seguindo-se a literatura de referência (Silva et al. 1990), será utilizado o termo aldeia para designar o local físico específico onde se deu um assentamento do tipo jazida paleoetnográfica.
Na primeira ocupação, representada por 17 esqueletos, o morto era depositado contra a parede interna da habitação, que forma um padrão circular com diâmetro entre 4 e $6 \mathrm{~m}$. Os esqueletos correspondentes a este padrão estão estendidos ao comprido, dispostos em decúbito lateral e com a cabeça voltada para o centro do círculo. Apenas um sepultamento apresentou material associado e apenas uma criança foi enterrada seguindo este padrão. Somente por comparação foi possível vincular este padrão à Tradição Itararé, uma vez que o sítio Praia das Laranjeiras II, um assentamento próximo reconhecidamente Itararé, apresenta padrão de sepultamento semelhante.

Na segunda ocupação, representada por 146 esqueletos, os mortos eram depositados em espaços delimitados que poderiam corresponder a cemitérios domiciliares, possivelmente cercados, limitando áreas que geralmente se configuram como quadriláteros. Há uma predominância de sepultamentos em decúbito ventral ou dorsal e a orientação dos corpos parece não seguir nenhuma orientação magnética específica, ainda que a disposição seja geralmente paralela ou subparalela. Muitos esqueletos que compõem este cemitério perturbaram enterramentos do primeiro padrão, indicando serem mais recentes do que aqueles.

Na terceira ocupação, representada por sete esqueletos e localizada dentro e fora dos cemitérios domiciliares, os indivíduos adultos estavam fletidos e pedras foram utilizadas para manter a posição do corpo. Alguns sepultamentos que seguiram este padrão perturbaram esqueletos depositados segundo o padrão anterior, indicando sua menor antiguidade em relação àqueles.

\section{Material e métodos}

Foram analisados todos os adultos em estado de conservação satisfatória e com o respectivo crânio, sendo 36 homens e 35 mulheres, em um total de 71 indivíduos.

As crianças e adolescentes não foram analisados principalmente em função do estado de conservação ruim. Por outro lado, considera-se aqui que esta faixa etária é menos informativa para os objetivos do estudo, uma vez que os indivíduos adultos normalmente se envolvem mais diretamente em episódios de violência. A expressão deste fenômeno sobre estes segmentos ocorreria apenas 
em casos muito específicos, uma vez que não tem sido observado em material arqueológico, ou em caso de guerras ou massacres (Walker 1997, 2001). Os padrões de sepultamento observados para o sítio não dão suporte a esta última hipótese (Rohr 1966).

As estimativas de sexo foram realizadas com base na morfologia do crânio e da pelve (Buikstra e Ubelaker 1994).

Foram considerados traumas agudos associados à violência aqueles tradicionalmente descritos na literatura especializada: fraturas em depressão no crânio, fraturas na face, fraturas na ulna (parry) e ferimentos causados por pontas de projétil (Steinbock 1976; Ortner e Putschar 1985; Walker 1989, 1997).

O diagnóstico das fraturas foi feito a partir da observação dos seguintes elementos diagnósticos, estabelecidos segundo critérios anátomo-patológicos (Steinbock 1976; Adams 1976; Merbs 1989; Ortner e Putschar 1985; Larsen 1997): alteração de modelação com afundamento, ausência e/ou reabsorção ósseas; solução de continuidade nas estruturas anatômicas; neoformação óssea com textura cortical superficial densa (processo cicatricial) ou textura cortical porosa (reabsorção ativa).

Entre as fraturas peri-mortem, apenas aquelas que apresentam fragmentos ósseos aderidos deslocados para dentro ocorreram enquanto o periósteo ou outro tecido mole encontrava-se intacto, sendo provavelmente a causa da morte do indivíduo (Ortner e Putschar 1985; Byers 2002). Entre estas últimas, serão considerados marcadores de violência as fraturas em depressão no crânio, com formato circular ou oval, reconhecidamente associadas a um golpe produzido por instrumento rombudo.

Em um caso de lesão causada por ponta de projétil, foi considerada a descrição e interpretação de $\operatorname{Rohr}(1966,1975)$ para um indivíduo que apresentou quatro pontas de flecha entre as costelas. É pouco provável que as pontas fossem acompanhamentos funerários, uma vez que não houve cuidado na forma de sepultamento. $\mathrm{O}$ esqueleto encontrava-se em decúbito dorsal, com a cabeça atirada para trás, o mento verticalmente para a frente, um braço levantado, um joelho dobrado e o pé sobre a tíbia da outra perna. Não foi possível realizar uma análise minuciosa nas costelas para verificar possíveis marcas de ferimento devido à ausência de algumas delas.
A quantificação das lesões teve como base a segmentação da amostra segundo sexo e momento de ocupação do sítio.

\section{Resultados}

Considerando-se o total de indivíduos analisados, cinco homens (13,9\%) e uma mulher (2,8\%) apresentam lesões associadas à violência. Quando a amostraé segmenta por momento de ocupação, observa-se que os episódios de violência ocorreram exclusivamente durante a segunda ocupação do sítio. As freqüências calculadas especificamente para esta amostra sobem para 17,2\% entre os homens e 3,8\% entre as mulheres (Tabela 1).

Tabela 1

Distribuição dos indivíduos que apresentam lesões associadas à violência segundo sexo e momento de ocupação do sítio - Praia da Tapera (SC)

\begin{tabular}{lrrrrrr} 
& \multicolumn{3}{c}{ Masculinos } & \multicolumn{3}{c}{ Femininos } \\
\cline { 2 - 7 } & $\mathbf{N}$ & $\mathbf{n}$ & $\mathbf{\%}$ & \multicolumn{1}{c}{$\mathbf{N}$} & $\mathbf{n}$ & $\mathbf{\%}$ \\
\hline 1 $^{\text {a } \text { ocupação }}$ & 3 & - & - & 7 & - & - \\
2 $^{\mathrm{a}}$ ocupação & 29 & 5 & 17,2 & 26 & 1 & 3,8 \\
3 $^{\mathrm{a}}$ ocupação & 4 & - & - & 2 & - & - \\
Total & $\mathbf{3 6}$ & $\mathbf{5}$ & $\mathbf{1 3 , 9}$ & $\mathbf{3 5}$ & $\mathbf{1}$ & $\mathbf{2 , 8}$ \\
\hline
\end{tabular}

$\boldsymbol{N}=$ número de indivíduos analisados $\boldsymbol{n}$ = número de indivíduos que apresentam lesão

Com relação ao tipo de lesão, os ferimentos causados por ponta de flecha (Figs. 1 e 2) apresentaram a maior freqüência entre os homens, representando $60 \%$ das lesões observadas. As fraturas de crânio (Figs. 3 e 4) representaram 40\% e 100\% das lesões observadas em homens e mulheres respectivamente. Não foram observadas fraturas na face ou na ulna em ambos os sexos (Tabela 2).

Tabela 2

Freqüência de lesões associadas à violência segundo sexo e tipo de ferimento sítio Praia da Tapera (SC)

\begin{tabular}{lcccc} 
& \multicolumn{2}{c}{ Masculinos } & \multicolumn{2}{c}{ Femininos } \\
\cline { 2 - 5 } Lesões & $\mathbf{n}$ & $\mathbf{\%}$ & $\mathbf{n}$ & $\mathbf{\%}$ \\
\hline \hline Crânio & 2 & 40 & 1 & 100 \\
Face & - & - & - & - \\
Parry & - & - & - & - \\
Flechada & 3 & 60 & - & - \\
Total & $\mathbf{5}$ & $\mathbf{1 0 0}$ & $\mathbf{1}$ & $\mathbf{1 0 0}$
\end{tabular}

\% calculado sobre o total de lesões observadas 


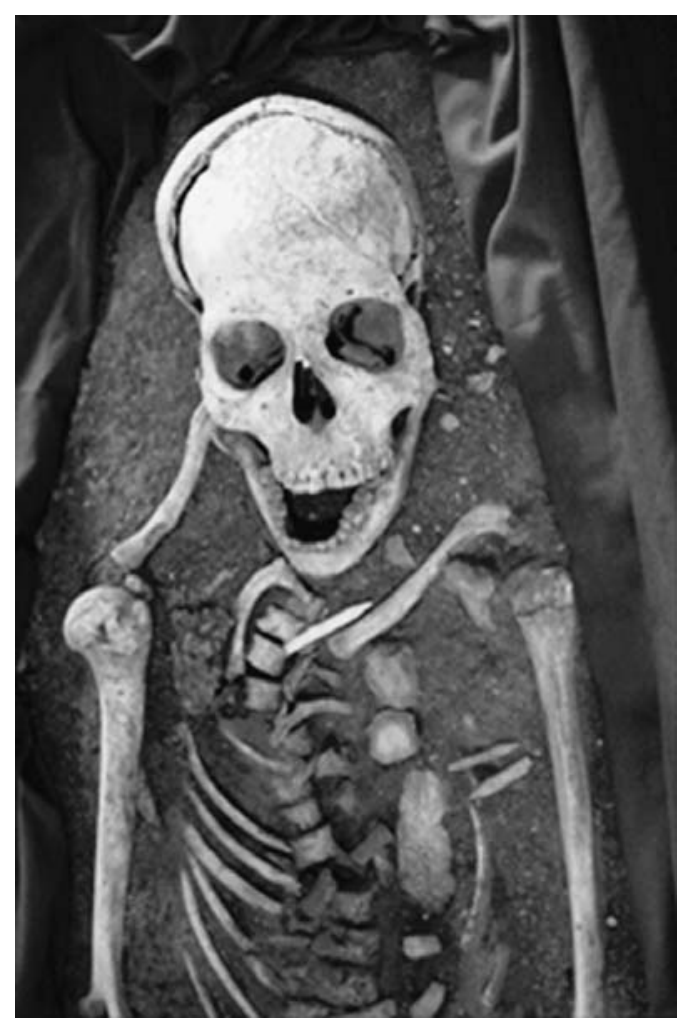

Fig. 1 - Indivíduo masculino (\# 110) apresentando a terceira vértebra dorsal perfurada por ponta de flecha confeccionada em osso. Note-se a trajetória de penetração da ponta de cima para baixo (Foto A. Lessa).

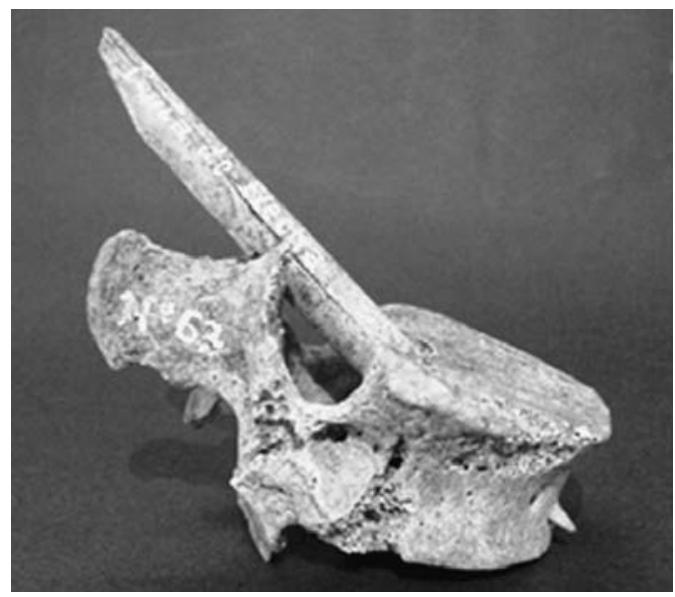

Fig. 2 - Indivíduo masculino (\#63) apresentando a décima segunda vértebra dorsal perfurada por ponta de flecha confeccionada em osso. Note-se a trajetória de penetração posterior (Foto A. Lessa).

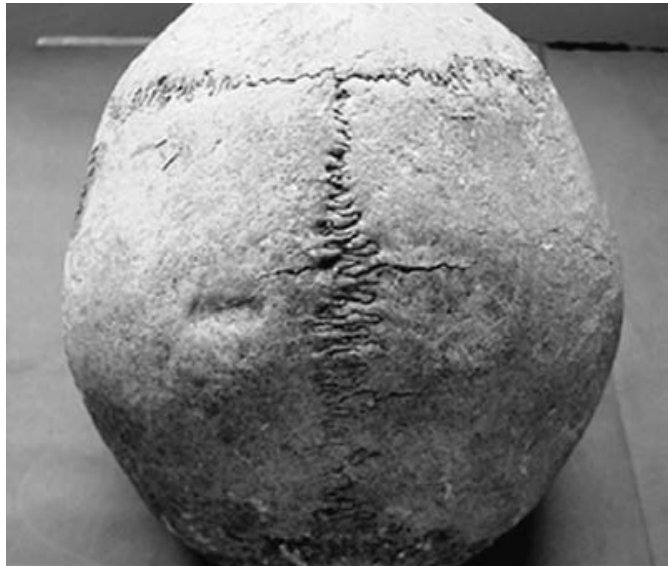

Fig. 3 - Indivíduo masculino (\# 34) apresentando fratura em depressão cicatrizada no occipital (Foto A. Lessa).

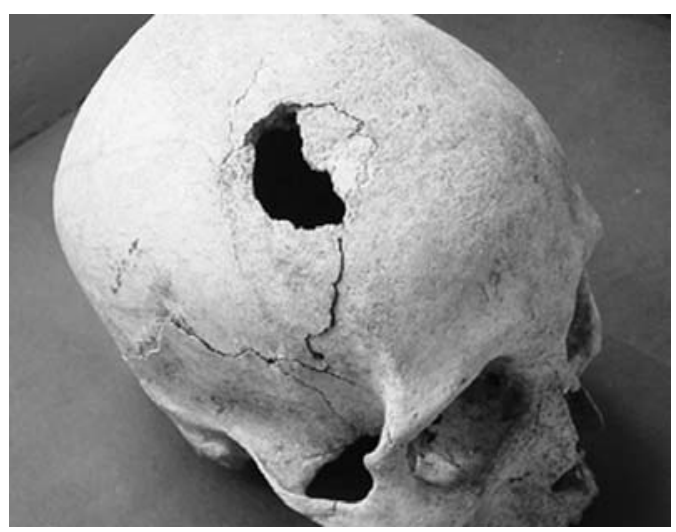

Fig. 4 - Indivíduo masculino (\#84) apresentando fratura peri-mortem no parietal direito (Foto A. Lessa).

\section{Discussão}

As freqüências de lesões observadas para a amostra de Praia da Tapera, com um valor expressivamente mais alto para os homens do que para as mulheres, segue o padrão observado para grupos caçadores-coletores e horticultores antigos e contemporâneos. Relatos etnohistóricos e estudos etnográficos atestam que os homens são normalmente os responsáveis pelas rixas inter e intragrupais. As mulheres, por sua vez, normalmente envolvemse em brigas dentro de um contexto doméstico, associado a assuntos do cotidiano, ou são vítimas 
de agressões durante raptos ou massacres durante a invasão de aldeias (Burbank 1992; Wranghan e Peterson 1996; Levinson 1989, apud Wilkinson 1997; Webb 1989). Estudos em populações préhistóricas em geral têm confirmado este padrão (Lambert 1997; Robb 1997; Frayer 1997; Lessa e Mendonça de Souza 2004; Lessa 2005).

O tipo de ferimento predominante, causado por pontas de flechas, sugere a ocorrência de conflitos intergrupais. Diversos estudos etnográficos demonstram que este tipo de arma é freqüentemente utilizado entre grupos com parentesco distante (Lambert, 1997). A trajetória de penetração das pontas, anterior, posterior e de cima para baixo, não apresenta um padrão específico e indica que as vítimas podem ter sido atingidas de surpresa, ou durante uma fuga. As três pontas, confeccionadas em osso, seguem o padrão observado para populações litorâneas, o que descarta a possibilidade dos agressores serem de grupos do interior.

De acordo com a distribuição dos padrões de sepultamento, fica claro que a segunda ocupação foi a mais intensa, e a distribuição das lesões, por sua vez, indica que este foi um período de conflitos. Comparando-se o percentual observado para os homens, de $17,2 \%$, com os percentuais observados para populações construtoras de sambaquis do litoral catarinense (Lessa e Medeiros 2001), fica mais evidente a magnitude do valor observado para a Tapera. As amostras provenientes dos sambaquis Jabuticabeira II e Forte Marechal Luz não apresentaram lesões, e a amostra proveniente do sambaqui de Cabeçuda apresentou um percentual de $4,8 \%$.

Neste primeiro estudo sobre grupos ceramistas litorâneos, ainda não é possível propor um padrão ou fazer generalizações sobre a questão da violência. No entanto, algumas hipóteses devem ser esboçadas para futuros testes com outras amostras.

Sob uma perspectiva mais geral, dois aspectos que separam as populações construtoras de sambaquis e as populações ceramistas que ocuparam as aldeias litorâneas podem estar associados à intensificação dos conflitos entre as últimas, caso este padrão seja confirmado para outras amostras. Estes aspectos certamente se associam à diferença temporal entre as ocupações nos dois tipos de sítios. Os sambaquis foram ocupados entre aproximadamente 6.000 anos atrás e o primeiro milênio da era cristã, e as aldeias litorâneas de grupos ceramistas correspondem a ocupações a partir do final do primeiro milênio.

Primeiramente, pode ser observada uma mudança no padrão de subsistência entre os dois tipos de sítios, passando de uma exploração intensa dos frutos do mar em geral, principalmente moluscos e peixes (Lima 1991; Bandeira 1992; Figuti 1993, 1996) e ausência ou raridade de fauna terrestre (Prous 1992), para uma maior diversificação alimentar que inclui, além da pesca, a caça de um grande número de mamíferos terrestres e aquáticos, o que se reflete na proliferação das pontas ósseas (Beck 1972; Tiburtius et al. 1950/ 51; Silva et al. 1990; Bandeira 1992; Schmitz et al. 1993; Schmitz 1996). ${ }^{2}$ Algumas hipóteses têm sido aventadas para a mudança no padrão de subsistência, como a de uma diminuição na oferta de alimentos marinhos em função das oscilações do nível do mar (Hurt 1974; Tenório 1995), ou ainda o esgotamento das colônias de moluscos provocado por um sistema altamente predatório e imprevidente de coleta (Lima 1999/2000).

É possível que esta mudança no padrão de subsistência tenha gerado conflitos durante a captação dos recursos. Segundo Perlman (1980), certos recursos marinhos apresentam a tendência de formarem zonas de recrutamento (grandes concentrações de uma espécie em áreas reduzidas) o que reduziria o espaço de dispersão para aquisição do alimento, diferentemente da disponibilidade observada para a Mata Atlântica, onde a fauna de mamíferos predominantemente solitários apresenta uma densidade por espécie/área baixa (Vickers 1984). A demanda por uma maior mobilidade para a procura por animais terrestres dentro da mata fechada do que para a coleta de moluscos e a pesca, certamente favoreceu o encontro de diferentes grupos de caçadores.

Por outro lado, os ambientes marítimos caracterizam-se geralmente por uma maior estabilidade ecológica do que os biótopos terrestres correspondentes dentro da mesma zona latitudinal, além de contarem com espécies migratórias que podem ser intensamente exploradas com alto

(2) As aldeias litorâneas mais antigas, sem presença de cerâmica, como Laranjeiras I (SC) e Pântano do Sul (SC) também apresentam restos faunísticos de mamíferos terestres em menor quantidade e diversidade do que as aldeias mais recentes ocupadas por ceramistas (Schmitz e Bitencourt 1996a, 1996b). 
rendimento (Yesner 1980), o que faz da caça uma atividade mais competitiva do que a pesca.

$\mathrm{O}$ outro fator que deve ser mencionado diz respeito à ideologia subjacente à atividade construtiva dos montes de conchas, uma vez que eles não teriam sido feitos de forma aleatória, mas certamente obedeceram a um projeto ideologicamente determinado (Gaspar 1992; Lima 1999/2000). É fato que esta ideologia confere certa unidade às populações construtoras de sambaquis, ainda que não se pretenda aqui ignorar deliberadamente as variações inerentes aos sub-sistemas que as compõem. Questões de caráter êmico, relacionadas a esse substrato ideológico, podem ter forjado um comportamento pouco agressivo a partir do desenvolvimento de outros mecanismos para resolução de conflitos. Paralelamente à falência do sistema sambaquiano e surgimento de uma nova ordem, onde já não importavam as premissas associadas à acumulação de conchas e observa-se a introdução de uma importante inovação tecnológica como a cerâmica, é possível que a agressividade tenha adquirido uma nova dimensão e importância entre as populações litorâneas.

Conforme mencionado anteriormente, estas explanações em âmbito geral têm um caráter ainda tentativo e provisório, dependente da confirmação de um padrão a partir da análise de outras amostras. Desta forma, parece oportuno considerar também uma reflexão mais particular para o sítio Praia da Tapera.

Em um momento de colapso de um milenar e bem sucedido modo de vida, provavelmente devido à redução na oferta dos recursos mais intensamente explorados, poderiam se intensificar as disputas por nichos estrategicamente localizados.

O assentamento da Tapera está localizado a poucos metros do mar, em uma enseada de águas calmas voltada para o continente e protegida dos ventos frios do sul. O lado noroeste da praia é atravessado pelo rio Êra, o qual teria condições de abastecer de água potável as populações ali assentadas. Um grande manguezal localiza-se atrás do sítio, a apenas $1 \mathrm{~km}$ da praia, estendendo-se por cerca de $4 \mathrm{~km}$ ilha adentro até atingir as desembocaduras de dois rios maiores. A uns dois quilômetros ao sul, onde está localizado o estuário de outro rio, ocorre uma extensa região de baixios, na qual a coleta de moluscos é ainda hoje realizada em quantidades consideráveis. Para a caça, seriam importantes especialmente a densa Mata Atlântica, que ocorria nos terrenos elevados que cercam o local por três lados, e os campos de planícies próximas, cobertas por vegetação mais baixa. Essas áreas também se prestariam para a realização de cultivos. Nas regiões circunvizinhas ao sítio, não são poucos os diques de diabásio diaclasado, e na beira do mar pode ser encontrada grande quantidade de seixos (Silva et al. 1990).

Ainda que não fosse o único a apresentar características semelhantes, esta convergência de recursos certamente atuou como um grande atrativo para o assentamento, possivelmente estimulando rixas para a sua ocupação ou exploração dos ambientes próximos.

Finalmente, vale mencionar uma segunda possibilidade de interpretação mais particular para a ocorrência dos conflitos no sítio.

Os habitantes da Tapera, pelo menos a partir do segundo momento de ocupação, faziam uso da cerâmica, a qual representava uma inovação tecnológica. No entanto, foram recuperados apenas 4.631 cacos, extremamente fragmentados, representando um pequeno número de vasilhames. Essa baixa densidade fica mais evidente quando comparada com os sítios Forte Marechal Luz, Enseada I e Laranjeiras II, todos localizados no litoral norte de Santa Catarina. Laranjeiras II, por exemplo, apresentou 5.551 cacos pouco fragmentados para uma área escavada quatro vezes menor, representando grande densidade cerâmica (Silva et al. 1990; Schmitz et al. 1993).

A partir desses dados é possível supor que o vasilhame não era produzido pelo grupo, mas possivelmente adquirido por meio de troca. $\mathrm{O}$ trabalho de Neves (1988) dá respaldo a esta hipótese uma vez que demonstrou afinidade genética entre os habitantes da Tapera e os construtores de sambaquis pré-cerâmicos do norte de Santa Catarina, descartando a possibilidade de este grupo ter migrado do interior e trazido consigo a tecnologia de fabricação da cerâmica, mas indicando uma migração litorânea no sentido nortesul. Os grupos que ocuparam Laranjeiras II e Enseada I, ao contrário, apresentam afinidade entre si, mas estão distanciados dos demais grupos litorâneos, sugerindo que possam ter migrado do interior.

O interesse na aquisição desta tecnologia poderia ser a causa de ataques dos homens da Tapera a aldeias ceramistas para o rapto de mulheres, as quais seriam preservadas de ataques 
mortais. O fato de a amostra feminina não apresentar ferimentos por pontas de flecha, mas apenas uma delas apresentar duas pequenas fraturas em depressão no crânio, indica que as mesmas não sofreram ferimentos letais e sugere que não houve ataques à aldeia, estando coerente com a hipótese proposta.

\section{Considerações finais}

Nesta primeira reflexão sobre a questão da violência em uma aldeia litorânea, foram colocadas quatro possibilidades de interpretação para o padrão de lesões observado, com uma freqüência mais alta entre os homens, nos quais predominam as flechadas, além de este valor ser mais alto do que aqueles observados para populações construtoras de sambaquis. A diversificação e uma maior competitividade na exploração de recursos e diferenças de caráter êmico com relação à ideologia subjacente às construções de conchas, são interpretações baseadas em aspectos gerais. A localização estratégica do assentamento e o domínio de uma nova e importante tecnologia, por outro lado, são interpretações mais particulares para o sítio.
Ainda que pesquisas futuras revelem um padrão de lesões geral no qual uma ou outra perspectiva se enquadre melhor, as interpretações não são necessariamente excludentes, uma vez que os momentos de tensão em uma sociedade estão normalmente inseridos em um contexto configurado por uma conjunção de fatores. Uma tentativa de identificação das particularidades de cada sítio, bem como de elementos culturais, espaciais, ecológicos e cronológicos convergentes, deverá nortear estudos futuros que visem o entendimento do fenômeno da violência sob uma perspectiva integradora. Compreender de que forma o homem convivia com o meio, com os membros do seu grupo, com vizinhos próximos e com inesperados visitantes pouco amistosos certamente contribuirá para a construção de um quadro mais consistente sobre o modo vida dos antigos habitantes do nosso litoral.

\section{Agradecimentos}

Ao professor Sidney Linhares, responsável pelas coleções depositadas no Museu do Homem do Sambaqui, Colégio Catarinense - Florianópolis, pela receptividade, atenção e interesse pela pesquisa.

LESSA, A. Preliminary thoughts on paleoepidemiology of violence in coastal ceramic groups: (I) Praia da Tapera Site - SC. Rev. do Museu de Arqueologia e Etnologia, São Paulo, 15-16: 199-207, 2005-2006.

ABSTRACT: It was analyzed the violent trauma in the skeletal sample from Praia da Tapera site (SC), composed by 71 adult males and females. Arrow wounds and skull, face and parry fractures were the violent lesions considered here. Only the individuals associated to the second moment of occupation of the site presented trauma, and the men were most affected than women (17.2\% and 3.8\% respectively). The preliminary interpretations for the occurrence of the conflicts are related to ideological elements and subsistence pattern in a general perspective. A more particular reflection for the site related the conflicts to it strategic location, or to the attempt of women abduction.

UNITERMS: Paleoepidemiology - Acute trauma - Violence - Ceramic groups Coast-Santa Catarina. 


\section{Referências bibliográficas}

ADAMS, J.C.

1976 Manual de Fraturas. São Paulo: Editora Artes Médicas.

BANDEIRA, D.R

1992 Mudança na estratégia de subsistência do sítio arqueológico Enseada I - Um estudo de caso. Dissertação de mestrado. Florianópolis, Universidade Federal de Santa Catarina.

BECK, A.M.

1972 A variação do conteúdo cultural dos sambaquis: litoral de Santa Catarina. Tese de Doutorado. São Paulo, Universidade de São Paulo.

BUIKSTRA, J.; UBELAKER, D.

1994 Standards for data collection from human skeletal remains. Arkansas: Arkansas Archaeological Survey.

BYERS, S.

2002 Introduction to Forensic Anthropology. Boston: Allyn \& Bacon.

BURBANK, V.

1992 Sex, Gender and Difference. Dimensions of Aggression in na Australian Aboriginal Community. Human Nature, 31: 251-278.

FIGUTI, L.

1993 O homem pré-histórico, o molusco e o sambaqui: considerações sobre a subsistência dos povos sambaquieiros. Rev. do Museu de Arqueologia e Etnologia, 3: 67-80.

FIGUTI, L.; KLÖKLER, D.M.

1996 Resultados preliminares dos vestígios zooarqueológicos do Sambaqui Espinheiros II (Joinville, SC). Rev. do Museu de Arqueologia e Etnologia, 6: 169-187.

FRAYER, D.

1997 Ofnet: Evidence for a Mesolithic Massacre. D.L. Martin; D.W. Frayer (Eds.) Troubled Times: Violence and Warfare in the Past. Amsterdan, Gordon and Breach Publishers: 181-216.

GASPAR, M.D.

1992 Aspectos da organização social de um grupo de pescadores, coletores e caçadores que ocupou o litoral do Estado do Rio de Janeiro. A.J.G. Araújo; L.F. Ferreira (Eds.) Paleopatologia e Paleoepidemiologia Estudos multidisciplinares. Rio de Janeiro, Editora Fiocruz: 95-110.

HURT, W.R.

1974 The interrelationship between the natural environment and four sambaquis, coast of Santa Catarina, Brasil. Occasional Papers and Monographs 1, Indiana University Museum, Bloomington.

\section{LAMBERT, P.M.}

1997 Patterns of Violence in Prehistoric Huntergatherer Societies of Coastal Southern
California. D.L. Martin; D.W. Frayer (Eds.) Troubled Times: Violence and Warfare in the Past. Amsterdan, Gordon and Breach Publishers: 77-110.

LARSEN, C.S.

1999 Archaeology - Interpreting behavior from the human skeleton. Cambridge: Cambridge University Press.

LESSA, A.

2004 Arqueologia da agressividade humana: a violência sob uma perspectiva paleoepidemiológica. História, Ciências, Saúde-Manguinhos, 11 (2): 279-296.

2005 Paleoepidemiologia dos traumas agudos em grupos atacamenhos: a violência sob uma perspectiva diacrônica. Tese de Doutorado. Rio de Janeiro, Escola Nacional de Saúde Pública, Fundação Oswaldo Cruz.

LESSA, A.; MEDEIROS, J.C.

2001 Reflexões preliminares sobre a questão da violência em populações construtoras de sambaquis: análise dos sítios Cabeçuda (SC) e Arapuan (RJ). Rev. do Museu de Arqueologia e Etnologia, 11: 77-93.

LESSA, A; MENDONÇA DE SOUZA, S.M.F.

2001 Convívio e conflito: história cotidiana da vida pré-histórica. Inteligência, 12: 18-31.

2004 Violence in the Atacama desert during the Tiwanaku period: social tension? International Journal of Osteoarchaeology, 14(5): 374-388.

LIMA, T.A.

1991 Dos mariscos aos peixes: um estudo zooarqueológico da mudança de subsistência na pré-história do Rio de Janeiro. Tese de Doutorado. São Paulo, Faculdade de Filosofia, Letras e Ciências Humanas, Universidade de São Paulo.

1999/2000 Em busca dos frutos do Mar: Os pescadorescoletores do litoral centro-sul do Brasil. Revista da Universidade de São Paulo, 44: 270-327.

MENDONÇA DE SOUZA, S.M.F.; CARVALHO, D.M.; LESSA, A.

2003 Paleoepidemiology: Is there a case to answer? Memórias do Instituto Oswaldo Cruz, 98 (Supl.1): 21-28.

MERBS, C.F.

1989 Trauma. M.Y. Iscan; K.A.R. Kennedy (Eds.) Reconstruction of life from the skeleton. New York, Alan Liss: 161-189.

NEVES, W.

1988 Paleogenética dos grupos pré-históricos do litoral sul do Brasil (Paraná e Santa Catarina). Pesquisas, Série Antropologia, 43.

ORTNER, D.J.; PUTSCHAR, W.G.J.

1985 Identification of Pathological conditions in 
Human Skeletal Remains. Washington: Smithsonian Instituition Press.

PERLMAN, S.

1980 An optimum diet model, coastal variability and hunter gatherer behavior. M.B. Schiffer (Ed.) Advances in Archaeological Method and Theory. New York, Academic Press, 3: 257-310.

PROUS, A.

1992 Arqueologia Brasileira. Brasília: Editora UnB.

ROBB, J.

1997 Violence and Gender in Early Italy. D.L. Martin; D.W. Frayer (Eds.) Trobled Times Violence and Warfare in the Past. Amsterdan, Gordon and Breach Plubishers: 11-144.

ROHR, A.

1966 Pesquisas Arqueológicas em Santa Catarina: I - Exploração sistemática do sítio da Praia da Tapera. Pesquisas, Série Antropologia, 15: 320.

1975 Os homicídios pré-históricos da Tapera, Florianópolis, SC. Livro da Família: 178-179.

SCHMITZ, P.I.; VERARDI, I.; DE MASI, M.A.; ROGGE, J.H.; JACOBUS, A.L.

1993 Escavações arqueológicas do Pe. João Alfredo Rohr, S.J. - O sítio da Praia de Laranjeiras II. Uma aldeia da Tradição ceramista Itararé. Pesquisas, Série Antropologia, 49.

SCHMITZ, P.I.; BITENCOURT, A.L.V.

1996a Escavações arqueológicas do Pe. João Alfredo Rohr, S.J. - O sítio arqueológico de Laranjeiras I, SC. Pesquisas, Série Antropologia, 53: 13-76.

1996b Escavações arqueológicas do Pe. João Alfredo Rohr, S.J. - O sítio arqueológico do Pântano do Sul, SC. Pesquisas, Série Antropologia, 53: 77- 123.

SCHMITZ, P.I.

1996 Escavações arqueológicas do Pe. João Alfredo Rohr, S.J. - Visão de conjunto dos sítios da Tapera, Armação do Sul, Laranjeiras I e II, Pântano do Sul e Cabeçudas. Pesquisas, Série Antropologia, 53: 183-190.

SILVA, S.B.; SCHMITZ, P.J.; ROGGE, J.H.; DE MASI, M.A.; JACOBUS, A.L.

1990 Escavações arqueológicas do Pe. João Alfredo Rohr, S.J. - O sítio arqueológico da Praia da Tapera: um assentamento Itararé e Tupiguarani. Pesquisas, Série Antropologia, 45.

\section{STEINBOCK, R.T}

1976 Paleopathological Diagnosis and Interpretation. Springfield, Thomas Publisher.

\section{TENÓRIO, M.C.}

1995 Estabilidade dos grupos litorâneos préhistóricos: uma questão para ser discutida. M. Beltão (Ed.) Arqueologia do Estado do Rio de Janeiro. Niterói, Arquivo Público do Estado do Rio de Janeiro: 43-50.

TIBURTIUS, G; BIGARELLA, J.J.; BIGARELLA, I.K. 1950/1951 Nota prévia sobre a jazida paleoetnográfica de Itacoara, (Joinville), Estado de Santa Catarina. Arquivos de Biologia e Tecnologia, 5-6: 315-346.

VICKERS, W.

1984 The faunal components of lowland South América hunting kills. Interciencia, 9 (6): 366-376.

WALKER, P.L.

1989 Cranial Injuries as Evidence of Violence in Prehistoric Southern California. American Journal of Physical Anthropology, 80: 313323.

1997 Wife Beating, Boxing, and Broken Noses: Skeletal Evidence for the Cultural Patterning of Violence. D.L. Martin; D.W. Frayer (Eds.) Troubled Times - Violence and Warfare in the Past. Amsterdan, Gordon and Breach Publishers: 145-180.

2001 A bioarchaeological perspective on the history of violence. Annual. Review in Anthropology, 30: 573-96.

WEBB, $S$.

1995 Paleopathology of Aboriginal Australians Health and Disease Across a Huntergatherer Continent. London, Cambridge University Press.

WILKINSON, R.G.

1997 Violence Against Women: Raiding and Abduction in Prehistoric Michigan. D.L. Martin; D.W. Frayer (Eds.) Troubled Times Violence and Warfare in the Past. Amsterdan, Gordon and Breach Plubishers: 21-44.

WRANGHAM, R.; PETERSON, D.

1996 O macho Demoníaco - As Origens da Agressividade Humana. Rio de Janeiro: Ed. Objetiva.

YESNER, D.R.

1980 Maritime Hunters-Gatherers: ecology and prehistory. Current Anthropology, 21 (6): 727-750. 